\title{
13 BETTER SAFE THAN SORRY? IN SEARCH OF AN INTERNET BUSINESS MODEL IN ONLINE ENTERTAINMENT
}

\author{
Ola Henfridsson \\ Center for Digital Business and Department of Informatics \\ Umeå University \\ S-901 87 Umeå \\ and Viktoria Institute, \\ Göteborg \\ Sweden \\ Helena Holmström \\ Center for Digital Business and Department of Informatics \\ Umeå University \\ S-901 87 Umeå \\ Sweden \\ Ole Hanseth \\ Department of Informatics \\ University of Oslo \\ Norway
}

\begin{abstract}
This paper presents an action case study of the process by which the Swedish computer game developer Daydream Software planned, developed, and implemented the business model for its new online game, Clusterball. In particular, the paper explores Daydream's choice between a radical business model and a conservative one for the game. Building on forecasts that "casual gamers" such as academics, business people, middleaged people, and women would become important for the future growth of the electronic games software industry, Daydream first pursued a radical business model, viewing the game as an "entertainment portal." However, in light of the perceived need of results and release, a more conservative business
\end{abstract}

The original version of this chapter was revised: The copyright line was incorrect. This has been corrected. The Erratum to this chapter is available at DOI: 10.1007/978-0-387-35489-7_33 
model, aimed at already experienced gamers, was implemented. In view of this critical choice, there were many different assumptions, beliefs, and opinions about customers, the appropriate choice of technology, and the nature of gaming in general among the staff and management at Daydream. The findings of this paper illustrate the tension between new business models and pre-existing social and technical conditions, and the study provides useful insights into the broader theme of balancing radical and incremental change in developing business-to-consumer commerce.

\section{INTRODUCTION}

Although there has been considerable growth of business-to-consumer (B2C) Internet commerce, this growth does not match the high expectations held by e-commerce actors such as investors, business analysts, and start-up companies. In fact, the discrepancy between expectations and actual growth has caused many of these actors severe problems. On the NASDAQ market, for instance, several e-commerce companies lost most of their market value during 2000.

A general problem seems to be to identify fruitful business models for $\mathrm{B} 2 \mathrm{C}$ commerce. This problem seems particularly prevalent among the range of actors who offer online entertainment or information services. In the music industry, for instance, the problem is manifested in the controversy over online distribution of music, where the Napster trial can be considered as a critical milestone for influencing what kinds of future business models will gain momentum. Besides legal and technical considerations, however, online entertainment providers are also faced with rapidly changing customer behavior. As an example explored throughout this paper, Datamonitor (1999) forecasts that the as yet unexploited potential of the electronic games software industry resides with "casual gamers" such as business people, academics, middle-aged people, and women, rather than the traditional "hard-core gamer" typified by the young male who is both technically skilled and very devoted to computer games.

In view of the forecasts of the electronic games software industry, the Swedish computer game developer Daydream Software's choice of business model for their new online computer game, Clusterball, was a critical one involving organizational and social considerations as well as technical ones. Would they pursue a radical strategy aiming at broader categories of players or would they pursue a conservative strategy aimed at hard-core gamers? At the time Clusterball was launched (in Summer 2000), Daydream had chosen to pursue a "better safe than sorry" strategy aimed at hard-core gamers. Despite the 
early and radical strategy to reach new customer segments, the chosen strategy was a result of exploiting an existing customer group as well as already working technology.

This paper presents an action case study (Braa and Vidgen 1999), where onsite intervention and participation were important components in the research process. Over a ten-month period (January through October 2000), in-depth studies were conducted at Daydream, including data sources such as participant observation, document review, website data, and interventions. The specific focus of the case study is the process by which Daydream planned, developed, and implemented the business model for their new online game, Clusterball. This process illustrates the tension between new business models and preexisting social and technical conditions, and it provides useful insights into the broader theme of balancing radical and incremental change efforts in developing $\mathrm{B} 2 \mathrm{C}$ commerce.

There are at least two reasons why this is important. First, while the case relates to the generic topic of radical and incremental change (Argyris and Schön 1996, Dewar and Dutton 1986, Ettlie et al 1984, Orlikowski 1993), it does so in the new context of $\mathrm{B} 2 \mathrm{C}$ commerce. Assuming that some of the business models pursued by $\mathrm{B} 2 \mathrm{C}$ companies can be regarded as radical in themselves, an assessment of their role and function on traditional markets might bring new light to the possibility of implementing radical change. Second, there are many voices debating the emerging digital economy from polarized positions. While such voices are important to define a new field of interest, research plays an important role in leveraging detailed and insightful case studies of leading practice. Crafted in accessible and applicable ways (c.f., Benbasat and Zmud 1999), such research can be useful for developing the practice of electronic commerce.

\section{THEORETICAL FRAMEWORK: CHANGE STRATEGIES AND BUSINESS MODELING}

In the management literature there tends to be a strong belief in the importance of radical change, where business process reengineering (BPR) can be considered as the paradigm example of change strategies based on this belief. Following BPR's radical orientation expressed in the title of Michael Hammer's (1990) famous paper in the Harvard Business Review, "Don't Automate, Obliterate," a great many organizational change projects adopted this strategy in the early BPR era. The notion of radical change, however, turned out to be somewhat problematic. Even though the benefits can be tremendous if you succeed in implementing a radically better model (business model, product, process, etc.) than the one you already have, the pursuit of radically changing existing organizations is quite challenging. Later on, even Hammer admitted that 
the BPR's central focus on radical change was misconceived. However, the belief in radical change is still strong among management consultants and in the management literature. In discussions about e-commerce, to which this paper is contributes, it is often the potential achievement of radical improvement in terms of profit and organizational performance that makes ideas about ecommerce so attractive. In one of the most popular books in the area, Blown to Bits by Evans and Wurster (2000), it is, for instance, argued that, "The only sure loser is the fast follower. Fast followers are always too late. It is better to be too early five times than to be too late once" (p. 97).

The praise of radical change is mostly found in normative literature aiming at selling new and profitable strategies to business managers. Literature more focused on empirical analysis of organizational change tells a different story, indicating that radical change is rare and that most projects aiming at such change either fail or achieve only moderate change. One strand of literature forwarding this view is the so-called "new institutionalism" in organizational studies (March and Olsen 1989; DiMaggio and Powell 1991; Scott and Christensen 1995). Using the institutional character of organizations as an explanatory vehicle, these studies often show why organizational change processes so often fail (Brunsson 1985). Institutionalism addresses the interdependencies between elements in our social, organizational, and technical world, which make radical change difficult. In this context, organizations are seen as institutions, i.e., as large networks of interdependent elements or actions, which again are embedded into larger institutional environments, i.e., a large number of external or inter-organizational networks. Each network is linked to other networks, which are further linked to other networks indefinitely. Changing large networks is very challenging because such networks are too large and complex to be changed instantly, suggesting that they can only be changed a few elements at a time. Because of the interrelation between elements, the change of one element can only be done with respect to its links to contextual elements. This phenomenon is often described as organizational inertia.

The resistance to change in large networks is a central topic within network economics or economics of information, which often is seen as the foundation of e-business and the "new economy" (Evans and Wurster 2000; Shapiro and Varian 1999). Inertia and resistance to change is also found to be a central aspect of large technological systems including information systems (Hanseth 2000; Henfridsson and Söderholm 2000; Hughes 1983).

The remainder of the paper presents a case where an entertainment provider, Daydream Software, aimed at radical change in terms of an Internet business model for its new online computer game. The case study will show how the company had to abandon its radical strategy in light of pre-existing social and technical conditions. The case study will also show how this observation can be accounted for from the earlier findings on change strategies. 


\section{RESEARCH STRATEGY AND METHODOLOGY}

\subsection{Research Methodology}

This research study can be broadly classified as interpretive IS research (Klein and Myers 1999; Orlikowski and Baroudi 1991; Walsham 1995a, 1995b). For the IS researcher interested in understanding information systems in cultural and social contexts, this orientation directs the focus to people's assumptions, beliefs, and desires. More specifically, however, the study represents a form of interpretive research that has been labeled action case research (Braa and Vidgen 1999). On the spectrum between understanding and change, action case study research can be ascribed a middle-position. In comparison to mainstream interpretivism, action case researchers devote more energy to being closely involved with the people and technologies that they study (Argyris et al. 1985, Bra aand Vidgen 1999). In fact, the knowledge developed in the practical day-today activity of the studied actors is frequently used to intervene in the research context. This type of intervention is referred to as "action taking" (Susman and Evered 1978); with proper evaluation and specification of the learning outcome, such action taking works as a crucial part of the process of gaining knowledge. The action taking in this particular study was twofold. First, there was an accessibility component. In view of the fact that Daydream is a small company with a minimum of formalized practices, we needed access to everyday decisions to capture the critical information. Needless to say, this required us to take a more active part in Daydream's practices than the role that is usually taken in mainstream interpretivism. The internalized knowledge acquired by being part of the subtle and tacit nature of everyday practice was important in interpreting what was going on at the research site. Second, there was an experimental component. We entered the case study with certain research questions associated with the radical business model in mind. At an early stage, when this model was gaining momentum at the research site, we were actors with certain influence over what was happening, making Daydream a kind of "organizational laboratory" (Braa and Vidgen 1999).

\subsection{Data Sources and Analysis}

Pursuing action case research, this study investigates the process by which Daydream Software planned, developed, and implemented the business model for their new online game Clusterball. The data sources used were of various kinds. First, in being an interpretive study of organizational and technological transformation, mainstream data sources such as participant observation and 
document review were used to obtain an understanding of the interpretations held and enacted by both organizational actors and customers. Participant observation was the most important source of data in this study. Within the range of this study, around 600 hours of participant observation have been conducted and documented as weekly field reports. Second, data sources such as e-mail conversations among staff (one of the authors had a Daydream e-mail account); postings in associated communities like the Clusterball community, ballsnatchers.com, and shareholders' corner; and Clusterball website data were used. Finally, as part of the action approach, and as specified above, the results of "action taking" were documented and filed as part of the filed notes.

The data analysis was conducted within the broader framework of "the hermeneutic circle" (see Klein and Myers 1999, pp. 71-73). The hermeneutic circle asserts that understanding stems from seeing the inter-relation between the whole and parts of the phenomenon studied (Bernstein 1983, pp. 131-139; Klein and Myers 1999). Basically, this means that our understanding of organizational change in the computer gaming industry is planned to progress as a result of iterating between the locally collected data in forms of transcripts and documents, and the shifting priorities in the computer gaming industry as a whole.

\section{CLUSTERBALL: AN ON-LINE GAME}

Daydream Software $\mathrm{AB}$ was founded in 1994 and is situated in Umeå in the north of Sweden. The company develops interactive entertainment for distribution over the Internet as well as over other digital media. Despite Daydream's early stock exchange quotation in 1996, it is still a small company employing no more than 65 people (October 2000), consisting of managers, people at the marketing department, game developers and web designers. Today, three products have been released on the market: Safecracker, Traitors Gate, and Clusterball.

While Safecracker and Traitors Gate are CD-based computer games, the new game, Clusterball, is an on-line game. In releasing Clusterball, Daydream introduced a new generation of computer games that are distributed, played, and paid for over the Internet. As part of Daydream's non-violence strategy, Clusterball is marketed as a sports game, in which the player flies a ship with which he or she can pick balls from designated places diffused in different 3D-landscapes (see Figure 1). Since the game is an on-line game, players from all over the world can challenge each other. 

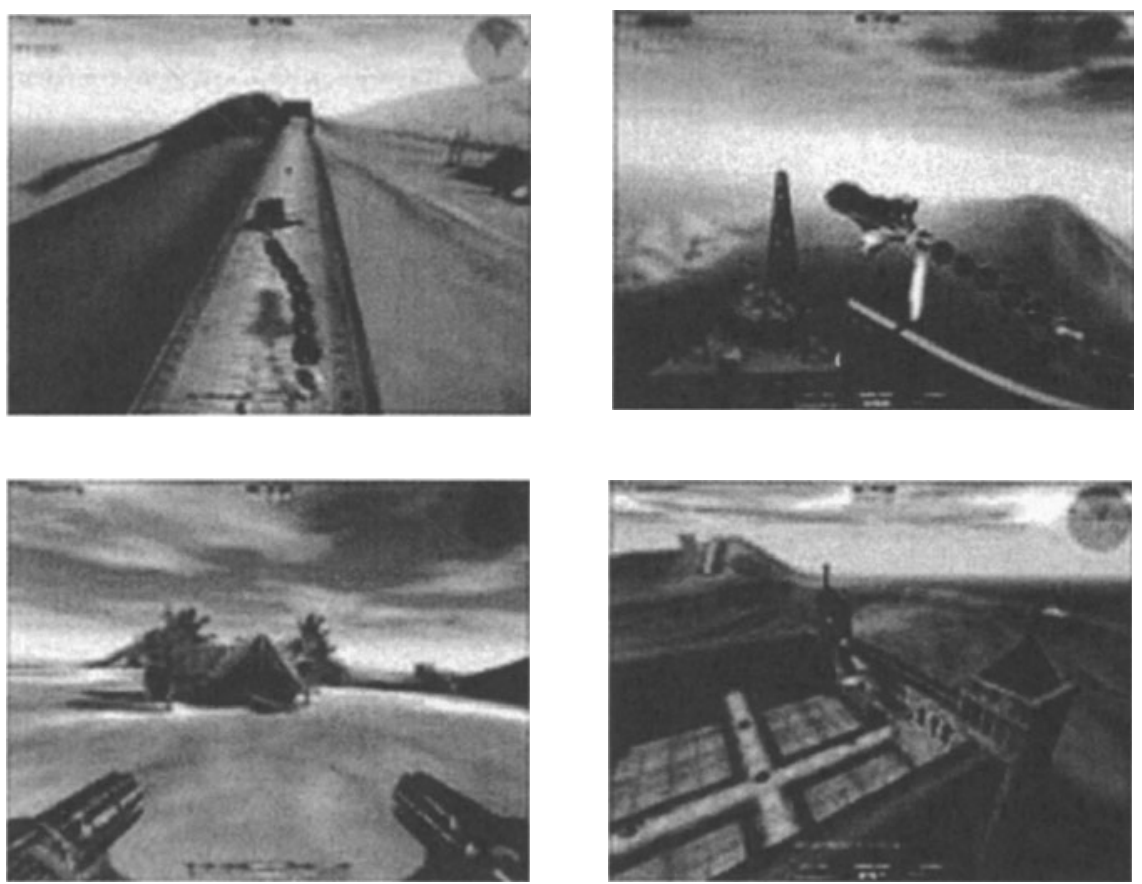

Figure 1. Screenshots from Four Different Clusterball Venues (Egypt, Antarctica, Bora Bora, Stonehenge)

Related to the game, there are technical features that make Clusterball interesting as a platform for on-line entertainment.

First, Daydream has developed a network protocol called Autobahn. This protocol makes it possible for computers connected to the Internet to exchange data independently of platform. In the case of Clusterball, gamers all over the world are connected to each other and the gaming events are experienced in real time.

Second, Daydream is an important content provider in the process of developing the Swedish Teleoperator Telias's version of the micro-payment system Jalda. ${ }^{1}$ Instead of supporting only single payment, this system makes it possible for the user to buy services on the Internet and to pay per unit of time or have the fee charged on either a credit card or a phone bill. Also, the user can get verification of the payment in a direct way via a mobile phone.

'PayIt builds on Jalda, which is a payment method standard developed by EHPT (Ericsson Hewlett-Packard Telecommunications). 
Finally, in cooperation with a local IT consultancy firm, Daydream has developed a Customer Relationship Management (CRM) database called Youmerang ${ }^{\mathrm{TM}}$. The CRM-system will handle personal information about the gamers as well as information about their behavior and results in each gaming session. The idea is that such information will help Daydream to learn about its customers in a way that will contribute to the future development of Clusterball and other products.

Taken together, these features distinguish Clusterball from other computer games, and strengthen the view of Clusterball as the beginning of something new in on-line entertainment.

\section{THE CRITICAL CHOICE: BETTER SAFE THAN SORRY?}

This section presents our understanding of Daydream's choice of business model for Clusterball. Following a brief presentation of the motivations and business model alternatives, the section spells out the details and assessments involved in this business decision in terms of three phases.

\subsection{The Critical Choice}

As suggested in the previous section, a successful release of Clusterball was critical to Daydream. There are several reasons why this was the case.

First, in view of Daydream's history of delayed games, a successful release of Clusterball would regain some of the stock market's slightly eroded trust in the company's capacity to meet expectations in terms of due dates. The company's first game, Safecracker, for instance, was severely delayed because of the economic disorder of the American game publisher Warner Interactive Entertainment. This was very unfortunate for Daydream, as Safecracker had received a lot of attention in relevant business and game magazines, creating a momentum for the game that could not be exploited because of Warner Interactive's problems. Given the Safecracker problems, there is little doubt that a successful release of Clusterball was perceived as important for Daydream. Second, the release of Clusterball would also work as a test of their new generation of games; in contrast to CD-based games such as Safecracker and Traitors Gate, these games are played, distributed, and paid for over the Internet. In being the first game in this new generation, Clusterball works as a platform for online entertainment containing several leading-edge technologies (described in section 4), and the release of Clusterball would be an important indication of 
the commercial as well as technical potential of this generation of games. Third, a successful release of Clusterball would facilitate Daydream's attempted transformation into a broader entertainment company. In the prospectus published before the new issue of shares in early 2000, Daydream presented a new overall strategy intended to broaden the business scope. This strategy was partly built on the fact that many of the technologies integrated in Clusterball could be expected to be applicable outside computer gaming. The leading knowledge about 3D graphics, for instance, was considered promising for application in virtual shopping centers. At a time when broadband technology has reached a critical mass of consumers, it can be considered likely that Daydream's knowledge about computer games will be able to be applied in new areas of business.

As described above, the release of Clusterball was critical to Daydream, involving a number of organizational, social, and technological considerations. One key issue was the choice of business model. There were basically two alternatives: a radical business model or a conservative one. In view of Datamonitor's (1999) forecast that most of the future growth of the computer gaming industry would come from occasional players, the so-called casual players, a business model oriented toward these players was an interesting alternative. The prospect of having women, businessmen, and middle-aged people playing Clusterball was very tempting in terms of both market share and business scope. This alternative was radical in the sense that Daydream, as most content providers on the market, had little experience of these customer groups. Even though hard-core gamers are expected to have a slower market growth, a much safer (and conservative) alternative would be to concentrate on these players. Drawing on the knowledge acquired when releasing Safecracker and Traitors Gate, Daydream knew this group fairly well.

\subsection{Radical and Conservative Change Strategies in the Case of Clusterball ${ }^{\mathrm{TM}}$}

The process of planning, developing, and implementing the business model for Clusterball involved different assumptions, beliefs, and opinions about customers, the appropriate choice of technology, and the nature of gaming in general. The process can be broadly divided into three phases. First, there was an initial and visionary phase in which a radical business model was pursued. At this early stage, Clusterball was thought of as an entertainment platform that would improve customer relations, attract new customer segments, and personalize entertainment services. Second, there was a phase of "make-and-sell" during which a more conservative business model was implemented. During this phase, 
existing business and technical conditions made it impossible to implement many of the early visions. Finally, after the release of the game, there was the evaluation phase during which the consequences of the chosen business model could be assessed. In the following sections, we present and explore the three phases.

\subsubsection{April 2000: Pursuing the Radical Business Model}

In early spring, Daydream pursued a radical business model viewing Clusterball as an "entertainment portal." Building on the perceived opportunities in the game and its related technologies, Daydream coined the slogan that became the dominating motto for the visionary phase of the Clusterball project: "It's not a game. It's an experience." In highlighting the experience over the gaming part, the CEO and the marketing department hoped to establish Clusterball as something more than a computer game. The vision of Clusterball as an entertainment portal was manifested in three sub-visions: the way in which Daydream sought to improve its customer relations; in Daydream's search for new customer segments; and in the efforts made to personalize the product through individual preferences.

First, an important theme concerned a redefinition of Daydream's relationship with its customers, where the border between developers and customers was intended to slowly blur. In line with the "open source" movement (see Ljungberg 2000; Raymond 1999), the customers would then be co-designers of the game, and Clusterball would be an online community for entertainment designers and consumers. In this way, Clusterball would be an interactive online experience in which flexibility and sensitivity would characterize the relation between Daydream and their customers. The core of the experience, the game, would continue to improve as more and more customers joined the community.

Second, the marketing department put efforts into exploring the potential of attracting new customer segments. In cooperation with the research group, the department spent considerable time on defining potential customer needs. Foremost, the discussions had to do with a group that Datamonitor calls casual gamers. A casual gamer could be described as a person who is fairly familiar with computers and has some experience of computer games. In this category of people, we would find children as well as adults, boys as well as girls, educated people as well as less educated people. For the marketing department, there were reasons to believe that this category would be the one with most business potential, since it includes a great variety of people, some with strong purchasing power. Consequently, many efforts were concentrated upon finding out what 
characterized the future casual gamer customer. An illustration of these efforts is the meeting held at the marketing department on April 11. The subject of the meeting was "teenagers" and the purpose was to find out what characterized this group of people, and in what way these characteristics could be reflected in Clusterball. By looking at other successful products directed toward children and teenagers (e.g., Barbie, Pokémon, Lego), it was believed that many important lessons could be learned.

Finally, inspired by one-to-one marketing ideas (see Peppers and Rogers 1997), Daydream put considerable effort into developing technologies, such as a CRM database and a virtual community that would enable personalization of Clusterball. These can be seen as important technical components in the realization of Clusterball as an entertainment portal. The CRM database was intended to make it possible to learn about specific customer segments, or even specific persons. The virtual customer community on the Clusterball website was intended to support and stimulate interaction between the gamers and in this way make it possible for Daydream to learn about the behavior and attitude of its customers.

In sum, the visionary phase reflects the focus upon casual gamers and the potential of this group as future customers. In enabling tightened customer relationships, new customer segments and means for personalization, Clusterball would be an entertainment portal from which on-line experiences could be downloaded and paid for in a flexible way.

\subsubsection{May 2000-July 17, 2000: Implementing the Conservative Business Model}

On May 4, a new member of the board was proposed with the intention to "strengthen the form of management and make it more business-oriented" (Daydream's group executive officer, press-release, May 4, 2000). In a similar vein, Daydream's group executive officer announced the appointment of the new marketing and sales executive a few days later with the comment that "this is a part of our strategy to recruit executives with a profitability profile." These announcements are good illustrations of the second phase of shaping the business model of Clusterball. The appointments of the new executive and the new board member were steps to bring into focus the marketing of the game instead of focusing discussions on future customer groups. In this phase, the praising of Clusterball and its related technologies had to be complemented with a "downto-earth" strategy to get the product on the market. "Make-and-sell" was a dominating motto of this phase-something that was manifested in a tightened schedule for the release of Clusterball. 
In light of the perceived quest for results and release, Daydream's management needed a business model that could be implemented rapidly. At that time, it was decided that Clusterball would be released with a more conservative business model instead of the radical one discussed in the previous visionary phase. There were two main reasons for doing this. First, it would not require as much time as the radical model in terms of development of related technologies. Many problems of a technological nature had already appeared. For instance, the micro-payment system proved to be impossible to use globally in an initial phase since partners and test environments had not yet been fully established. This situation eroded some of the vision about the radical model as a technically advanced business model. If released with the conservative model, Clusterball would not include technologies such as the CRM database and the micro-payment system in an initial phase. Instead, the conservative business model would focus on the game as it was, and facilitate an immediate release of Clusterball. Second, instead of the vaguely defined casual gamer, the conservative business model aimed at hard-core gamers. This customer group was already familiar to the company and the game industry. Besides technical skills and devotion to computer games, the hard-core gamers also had the power to diffuse news about Clusterball's up-coming release to other gaming communities on the web, an opportunity that could not be enjoyed to the same extent if focusing on the casual gamers. These arguments triggered the management to discredit the radical model aimed at the casual gamer and instead focus on a rapid release of the game to the hard-core community.

However, the vision about the casual gamer and a radical business model that incorporated advanced technology was not abandoned. On May 17, a strategic agreement was signed between Daydream and the Swedish teleoperator Telia saying that both parties would cooperate to facilitate future micropayments in Clusterball. Meanwhile, traditional credit card payment would be used, and the vision of "paying per experience" was reduced to the possibility of paying per venue (the game consists of 12 different venues and by using your credit card, you can purchase different venue packs). In this way, the idea of the casual gamer was put aside. An agreement was signed on June 16 between Daydream and IBM, in which it was decided that the IBM DebiTech system for credit card payments would be used globally for purchasing Clusterball.

The shift in focus from the casual gamer to hardcore gamers not only affected the payment system, but it also had implications for the planned usage of the customer database. The idea of collecting large amounts of customer data was not met with sympathy by the developers, as they knew hard-core gamers are "suspicious" by nature. Daydream would suffer, they argued, from the fact that hardcore gamers would not care to register without being allowed to test Clusterball. Therefore, an alternative was suggested in which some part of the game was free of charge. In this way, gamers could be attracted to the game, try 
the game out, and register in the database if they considered the game worth playing.

In sum, many components of the radical business model were scrapped in order to get Clusterball on the market. Instead of advanced technologies such as the CRM database and a micro-payment system intended for casual gamers, the business model chosen was a conservative one focusing on the already experienced gamers, in which traditional credit card payments would be used.

With the business model decided, and the IBM system for payments ready, the group executive officer stated that, "By solving the problem with the payment system, we are now ready to put Clusterball on the global market" (press release, June 29, 2000), announcing that Clusterball would be available for downloads by July 17 at 2:00 p.m.

\subsubsection{July 17, 2000-October 2000: After the Release}

As announced by the CEO, the base version of Clusterball was free for download on July 17. "Yes, it's a future sports on-line game. Action-packed and highly addictive, playable on any road and speed on the 'information highway.' The base version of Clusterball is free and downloadable right here" (clusterball.com July 17, 2000). In line with the more conservative business model that was finally chosen, the first venue could be downloaded free of charge and without having to register in the customer database. The second venue could also be downloaded for free, but gamers first had to register in the customer database.

The time following the release of Clusterball was dominated by campaigns, publicity stunts, and presentations succeeding each other. As expected, there was considerable interest in both the game itself and the integrated technologies, and the management at Daydream had reason to believe that the potential market for Clusterball would grow substantially.

However, despite continuous growth of registered customers, Daydream started to realize that there were certain problems associated with the business model chosen. First, the possibility of downloading the first venue for free without having to register in the customer database brought with it a large number of unknown customers. Without a verification of players, it was impossible for Daydream to estimate the total number of Clusterball players. Further, without records of the customers, there was no possibility to learn about the customers, their preferences and needs. Second, the possibility of enjoying the first venue for free did not stimulate purchase of the other venue packs. This resulted in a limited number of players on some of the venues, a fact that was brought to attention not only by people at Daydream but also among players in the Clusterball community. "In prime-time gaming time, there are often no more than 10 players on my server list" ("Muerte," ballsnatchers.com, August 31, 
2000). This problem worried the active gamers since it was hard to find new players to challenge. The limited number of active gamers started to become a community that knew each other and there was a risk of not attracting new players to the game. "The small click that are champs keep getting better and better while the less good players get scared of playing on-line" ("Muerte," ballsnatchers.com, August 31,2000). Due to the fact that the first venue was free of charge and did not require customer registration, the rate of purchase was low at the same time as the number of unknown customers playing the first venue was estimated to be high. There are reasons to believe that the balance between attracting hard-core gamers by distributing one venue at no cost without registration requirements, and making people motivated to purchase the following venue-packs and register in the customer database, was difficult to attain.

To address problems associated with the business model, a boxed version (CD) of Clusterball was planned for the autumn of 2000. This distribution channel would attract customers who would rather purchase a physical product than download the game as a file from the Internet. At this point, the Daydream management realized that on-line distribution of computer games was still in its infancy and the initial expectation that people would move away from physical distribution as rapidly as the technology allowed was mistaken. By providing a CD version consisting of a limited set of venues and the link to the Clusterball website, Daydream hoped to inspire the buyers of the physical product to continue to enjoy the product on-line.

The CD version of the game would also be used in order to penetrate new markets. During the months following the on-line release, Daydream worked intensively to establish agreements with distributors around the world. On September 21, an agreement was signed between Daydream and one of Gemany's leading publishers in interactive media, Infomedia Software Publishinng GmbH. This meant that the distribution, maintenance, and publicity of Clusterball in Germany would be handled by Infomedia, who would also take total responsibility for the German version of the Clusterball website. "The agreement with Infomedia opens for an enormous market... according to careful estimates we will sell 50,000 CDs only in an initial phase" (group executive officer of Daydream, September 21, 2000).

\section{BETTER SAFE THAN SORRY? YES!}

Research within the broad range of the digital economy is still at an early stage. While promising work has been devoted to analyzing the social and economic changes of the digital economy (see Castells 1996; Kelly 1998; Orlikowski 1999), this research study explores Internet business models. This is an attempt to trace how the broader themes relate to the lower level of business processes and organizational change. As a conclusion, we will try 
answering the question in the title of the paper: better safe than sorry? Our answer is: Yes!

The case study illustrates how radical change can be very challenging in the electronic games software industry. Daydream created a vision for a new product drawing extensively upon possibilities opened up by the Internet and related technologies: a game that could be played and distributed over the net; one-toone marketing strategies based on CRM systems; new micro payment technologies; and so on. Using these technologies, they believed they would be able to reach a new huge market of casual gamers. So far, their strategy was perfectly in line with popular management and e-business literature (e.g., Evans and Wurster 2000). The product and marketing strategy for Clusterball was definitely a radical break compared to their existing ones based on physical distribution and publishing. However, rather soon they realized that the break was too radical. It would certainly take too much time before the technology would work properly. First, the technological solution was a brand new one, and accordingly there was significant uncertainty about how to build it, how it would work in the end, etc. The micro payment infrastructure is currently not up and running and it is uncertain when that will happen. This infrastructure will have to be established by other organizations outside the control of Daydream. Second, there is considerable uncertainty related to the so-called casual gamers. Despite promising forecasts, they currently do not exist. They have to be constructed together with the games, including the distribution channels and payment systems, they are going to use (see Woolgar 1991). What kinds of games, distribution channels, and payment systems they will prefer, what kind of information they are willing to let the game developers store in their CRM systems, and so on, will be determined during the construction process. For these reasons, the implementation of the radical strategy will take considerable time. It is a process of high uncertainty-adaptations have to be made for a lots of unforseen events and lots of issues have to be dealt with during the process. Accordingly, trying to implement this strategy in one step-a big bang-would certainly fail.

For these reasons, Daydream's decision to target the product to their existing market, the hard-core gamers, was a wise one. In doing this, they soon had a product they could deliver globally. This strategy is conservative compared to the initial, radical one, although it was not that conservative since the game still embraced numerous new features, and advanced technologies for distribution over the net, payment structure, etc. These new features also had to be redesigned through an experimental learning process as customers started to use the game. This experimental process contained elements of tinkering, bricolage (Ciborra 1996), and improvisation (Ciborra 1999; Orlikowski 1996). By redesigning the technology to fit the requirements uncovered by the users' 
behavior and preferences, new ways of utilizing the new features of the product emerged and were implemented. This process might well be seen as the beginning of an experimental design and learning process which in due time will implement the radical vision originally created for Clusterball. In that sense, we can see radical change as taking place over time--better described as a continuous evolution than a big bang.

We believe Daydream's experiences are valid for a wide range of e-business cases. "First time right" has proved to be a rare achievement in software development as well as in the design of any other material or immaterial artifact. Design is always an experimental learning process, something evident also in the design of a new e-business. As in the case described in this paper, there are many elements that have to be designed in relation to each other. Components like the game Clusterball, the software and technologies behind it, the marketing strategy, the new payment infrastructures, the CRM database, and web sites supporting the virtual community for players will be important parts of many ebusiness solutions. These components are all interrelated and linked together into a complex network of actors. All elements, as well as the overall actor network, will have to be designed trough trial and error, a time consuming experimental learning process. Considering this, the conclusion is that radical change strategies are risky to embark on also in the establishment of e-business. In general, it holds that the more radical the strategy is, the more there is to learn, and the more important a conservative strategy in terms of change through a series of small steps.

The general experience from implementing e-business in Scandinavia seems to confirm this. A large number of new "e-business companies" were set up trying to implement radically new business models. Many of them are now in deep trouble if not broke. However, the movement toward "the new economy" where e-businesses are playing major roles seems to continue. This movement is now led by traditional companies slowly transforming their old business models into new ones, where radically different models are the long-term objectives. Most likely, Daydream's vision to change computer gaming will gain a lot from the chosen step-by-step procedure, where different components of the overall actor network are changed on an experimental basis.

\section{ACKNOWLEDGMENTS}

The Bank of Sweden Tercentenary Foundation, Daydream Software, and the European Union funded this work. Thanks are due to Philip Grey, Rikard Lindgren, Annakarin Nyberg, the program co-chairs, and two anonymous reviewers for useful comments on earlier versions of this paper. 


\section{REFERENCES}

Argyris, C., Putnam, R., and McLain-Smith, D. Action Science, San Francisco: Jossey-Bass, 1985.

Argyris, C., and Schön, D. A. Organizational Learning II: Theory, Method, and Practice, Reading, M: Addison-Wesley, 1996.

Benbasat, I., and Zmud, R. W. "Empirical Research in Information Systems: The Practice of Relevance, MIS Quarterly (23:1), 1999, pp. 3-16.

Bernstein, R. J. Beyond Objectivism and Relativism: Science, Hermeneutics, and Praxis, Philadelphia: University of Pennsylvania Press, 1983.

Braa, K., and Vidgen, R. "Interpretation, Intervention and Reduction in the Organizational Laboratory: A Framework for In-context Information Systems Research," Accounting, Management and Information Technologies (9), 1999, pp. 25-47.

Brunsson, N. The Irrational Organization, New York: Wiley, 1985.

Castells, M. The Rise of the Network Society (Volume 1), Malden, MA: Blackwell, 1996.

Ciborra, C. "Introduction: What Does Groupware Mean for the Organizations Hosting It?" Groupware and Teamwork, New York: John Wiley \& Sons, 1996, pp. 1-19.

Ciborra, C. U. "Notes on Improvisation and Time in Organizations," Accounting, Management, and Information Technologies (9), 1999, pp. 77-94.

Datamonitor. "Electronic Games: Booming Prospects for the New Millennium," Datamonitor, 1999.

Dewar, R. D., and Dutton, J. E. "The Adoption of Radical and Incremental Changes: An Empirical Analysis," Management Science (32:11), 1986, pp. 1422-1433.

DiMaggio, P. J., and Powell, W. W. (eds.). The New Institutionalism in Organizational Analysis, Chicago: The University of Chicago Press, 1991.

Ettlie, J., Bridges, W., and O'Keefe, R. D. "Organization Strategy and Structural Differences for Radical versus Incremental Innovation," Management Science (30:6), 1984, pp. 682-695.

Evans, P., and Wurster, T. S. Blown to Bits: How the New Economics of Information Transforms Strategy, Boston: Harvard Business School, 2000.

Hammer, M. "Reengineering Work: Don't Automate, Obliterate," Harvard Business Review, July/August 1990, pp. 104-112.

Hanseth, O. "The Economics of Standards," in From Control to Drift: The Dynamics of Corporate Information Infrastructures, C. Ciborra, K. Braa, A. Cordella, B. Dahlbom, A. Failla, O. Hanseth, V. Hespø, J. Ljungberg, E. Monteiro, and K. A. Simon (eds.), Oxford: Oxford University Press, 2000, pp. 56-70.

Henfridsson, O., and Söderholm, A. "Barriers to Learning: On Organizational Defenses and Vicious Circles in Technological Adaptation," Accounting, Management, and Information Technologies (10:1), 2000, pp. 33-51.

Hughes, T. P. Networks of Power: Electrification in Western Society, 1880-1930, Baltimore: John Hopkins University Press, 1983.

Kelly, K. New Rules for the New Economy, London: Fourth Estate, 1998.

Klein, H. K., and Myers, M. D. "A Set of Principles for Conducting and Evaluating Interpretive Field Studies in Information Systems," MIS Quarterly (23:1), 1999, pp. 67-93.

Ljungberg, J. "Open Source Movements as a Model for Organizing," European Journal of Information Systems (9:3), 2000, pp. 208-216.

March, J. G., and Olsen, J. P. Rediscovering Institutions, New York: The Free Press, 1989.

Orlikowski, W. J. "CASE Tools as Organizational Change: Investigating Incremental and Radical Changes in Systems Development," MIS Quarterly (17:3), 1993.

Orlikowski, W. J. "Improvising Organizational Transformation Over Time: A Situated Change Perspective," Information Systems Research (7:1), 1996, pp. 63-92. 
Orlikowski, W. J. "The Truth is Not Out There: An Enacted View of the "Digital Economy," presentation at "Understanding the Digital Economy: Data, Tools, and Research," Department of Commerce in Washington, DC, May 25-26, 1999 (http://mitpress.mit.edu/ ude.html, May 10, 2000).

Orlikowski, W. J., and Baroudi, J. J. "Studying Information Technology in Organizations: Research Approaches and Assumptions," Information Systems Research (2:1), 1991, pp. 128.

Peppers, D., and Rogers, M. Enterprise One-to-One: Tools for Building Unbreakable Customer Relationships in the Interactive Age, London: Piatkus Books, 1997.

Raymond, E. S. The Cathedral and the Bazaar: Musings on Linux and Open Source by an Accidental Revolutionary, Cambridge, MA: O'Reilly, 1999.

Scott, W. R., and Christensen, R. (eds.). The Institutional Construction of Organizations: International and Longitudinal Studies, London: Sage, 1995.

Shapiro, C., and Varian, H. R. Information Rules: A Strategic Guide to the Network Economy, Boston, MA: Harvard Business School Press, 1999.

Susman, G., and Evered, R. "An Assessment of the Scientific Merits of Action Research," Administrative Science Quarterly (23), 1978, pp. 582-603.

Walsham, G. "The Emergence of Interpretivism in IS Research," Information Systems Research (6:4), 1995a, pp. 376-394.

Walsham, G. "Interpretive Case Studies in IS Research: Nature and Method," European Journal of Information Systems (4), 1995b, pp. 74-81.

Woolgar S. "Configuring the User: The Case of Usability Trials," in A Sociology of Monsters: Essays on Power, Technology and Domination, J. Law (ed.), London: Routledge, 1991, pp. 57-99.

\section{About the Authors}

Ole Hanseth has spent most of his career in industry and applied research before moving to his current position as an associate professor at the Department of Informatics at the University of Oslo. He also held a part-time position at Göteborg University. The main focus of his research has been comprehensive, integrated, and geographically dispersed information systems - information infrastructures-in both the private and public sectors. Recent journal publications on these issues have appeared in Computer Supported Cooperative Work; Information Technology and People; Accounting, Management, and Information Technology; Science, Technology and Human Values; Systèmes d'Information et Management; and Scandinavian Journal of Information Systems. Ole can be reached by e-mail at ole.hanseth@ifi.uio.no.

Ola Henfridsson is the program manager of the Center for Digital Business at Umeå University. $\mathrm{He}$ is an assistant professor in the Department of Informatics at Umeå University and holds a part-time position at the Viktoria Institute, Göteborg University. Ola is a member of the editorial board of Scandinavian Journal of Information Systems and he has published his research in journals such as Accounting, Management, and Information Technologies and Information Systems Journal. Ola can be reached by e-mail at Ola.Henfridsson@, informatik.umu.se. 
Helena Holmström is a Ph.D. student in Informatics at the Center for Digital Business at Umeå University. She is also a lecturer at the Department of Informatics at Umeå University and teaches courses in systems design and electronic commerce. Her research interests focus on organizational aspects of electronic commerce and challenges in establishing and maintaining digital customer relationships. Helena can be reached by e-mail at Helena.Holmstrom@ informatik.umu.se. 